\title{
Current perspectives on the optimal age to spay/castrate dogs and cats
}

This article was published in the following Dove Press journal:

Veterinary Medicine: Research and Reports

8 May 2015

Number of times this article has been viewed

\section{Lisa M Howe}

Department of Small Animal Clinical Sciences, College of Veterinary Medicine and Biomedical Sciences, Texas A\&M University, College Station, TX, USA
Correspondence: Lisa M Howe Department of Small Animal Clinical Sciences, College of Veterinary Medicine and Biomedical Sciences, Texas A\&M University, College Station, TX 77843-4474, USA

Tel + I 979845235 I

Fax + I 9798456978

Email lhowe@cvm.tamu.edu
Abstract: Spaying and castrating of dogs and cats has been considered for decades to be a routine standard of practice in veterinary medicine in the US for the prevention of numerous undesirable behaviors, medical conditions, and diseases. Additionally, the procedures have been promoted as a method of curbing the severe pet-overpopulation problem in the US. Recently, however, this routine practice has come under scrutiny and become a very controversial topic. The general wisdom and safety of the procedures have been questioned by those who are concerned that the procedures may have some unintended consequences that are only recently being recognized. The purpose of this paper is to critically examine the scientific literature regarding elective spay/castration procedures and present both risks and benefits of elective gonadectomy. After the literature is examined, it becomes clear that there may not be a single absolute optimal age to spay or castrate all dogs and cats, but that the optimal age may be dependent upon several factors, including species, breed, body size, and breed-specific diseases, among others. Determining the optimal age to perform elective gonadectomy is much clearer in cats, and the literature demonstrates that the procedures can typically be safely performed at any age after 6-8 weeks of age. The optimal age to spay or castrate dogs of certain breeds (rottweiler, golden retriever, Labrador retriever, and vizsla) is becoming less clear as studies are being conducted as to the health benefits and risks in those breeds. This review will examine these controversies and make recommendations as to the optimal age to spay/castrate dogs based upon the scientific literature.

Keywords: gonadectomy (neuter), ovariohysterectomy (spay), castration, neoplasia, longevity, orthopedic disorders

\section{Introduction}

In veterinary practice, surgical sterilization of cats and dogs is one of the most common surgical procedures performed. Routine spaying/castrating is often performed because of its value in preventing reproductive tract disease, including pyometra and mammary neoplasia in female cats and dogs, and benign prostatic hyperplasia and testicular neoplasia in male dogs. ${ }^{1-8}$ Elective gonadectomy is also routinely performed in shelter situations in animals as young as 6-8 weeks of age as a method of contraception to help with the pet-overpopulation problem in the US. ${ }^{9-12}$ However, recently the routine practice of sterilizing all nonbreeding animals has come under scrutiny.

Veterinarians attempting to determine best practice for spaying/castrating of cats and dogs are often confronted with conflicting findings from various studies, as well as differences of opinion as to the optimal age to perform these procedures. The purpose of this review is to assimilate the literature, identify the risks and benefits of elective spaying/castrating in dogs and cats, and summarize and discuss these findings, as well 
as attempt to answer the question: when is the optimal age to spay or castrate dogs and cats?

\section{Considerations for spaying/ castrating}

In the current literature, there have been recent studies examining the effects of gonadectomy on dogs of certain breeds, and results suggest that hormones may have an influence on the risk of some types of neoplasia (both positively and negatively) and certain orthopedic disorders. Additionally, longevity appears to be influenced by neuter status in the general population of dogs. There are also many older "landmark" studies that are still referenced and relevant to discussions of the risk of neoplasia, as well as the more general risks and benefits of spaying/castrating in male and female dogs and cats. The following subsections will examine some of the more relevant, and sometimes controversial, issues facing the veterinarian making recommendations to clients regarding elective gonadectomy in the dog and cat.

\section{Reproductive neoplasia}

Mammary neoplasia is among the most common types of cancer seen in intact female dogs, and approximately $50 \%$ of these neoplasms are malignant. ${ }^{13,14}$ There may be differences, however, in the risk of malignancy among different sizes of dogs. With small-breed dogs, the risk of histologically malignant mammary tumors is $25 \%$, while the risk is $58 \%$ in large-breed dogs. ${ }^{15}$ It is believed that if a female dog is spayed after the second estrus cycle or after reaching 2.5 years of age, the relative risk of developing mammary neoplasia is $26 \%{ }^{1}$ In the boxer breed, there is a $45 \%$ risk of developing mammary neoplasia, and in the beagle breed the lifetime risk for the development of mammary neoplasia is $63 \%$, and the risk for developing a malignant tumor is $23 \%{ }^{16-18}$ It has also been shown that ovariohysterectomy at the same time as mastectomy in dogs that have already developed mammary neoplasia may improve the odds of preventing new mammary tumor formation. ${ }^{19}$ However, one recent systematic review of the literature based on Cochrane guidelines found that the association between the age at spaying and the risk of mammary neoplasia was weak. ${ }^{20}$ Depending upon the timing of gonadectomy, spaying female dogs prevents this potentially deadly neoplasm (Table 1).

Mammary tumors are also common in intact female cats, but the risk of mammary tumors is approximately half that of dogs. ${ }^{2,21}$ Unfortunately, between $85 \%$ and $93 \%$ of these tumors are malignant, and more than $80 \%$ of cats with malignant mammary tumors also have evidence of metastasis (Table 1). Cats spayed before a year of age are reported to have an $86 \%$ reduction in risk of developing mammary neoplasia compared to intact cats. ${ }^{3,21}$ As with dogs, appropriately timed gonadectomy in cats is extremely beneficial in preventing mammary neoplasia. ${ }^{3,21}$

In the male dog, castration prevents testicular neoplasia, although it has been estimated that less than $1 \%$ of intact male dogs will die of testicular cancer. ${ }^{22,23}$ This low death rate is due to a high cure rate coupled with the fairly low risk. Cats very rarely develop testicular neoplasia. ${ }^{24}$

Confusion sometimes exists regarding the effect of castration on prostate cancer in dogs. Castrated dogs are at an increased risk of developing prostate neoplasia. ${ }^{25}$ Fortunately, the risk of prostatic neoplasia is extremely low $(0.6 \%)$, negating undue concern about this risk. ${ }^{25}$

\section{Nonneoplastic reproductive disorders}

Pyometra is a life-threatening disease seen in unspayed dogs and cats, but the disease is much more frequent in dogs than in cats. ${ }^{4,5,26,27}$ The risk of pyometra in unspayed dogs has been reported to range from $25 \%$ to $66 \%$ in dogs over 9-10 years old, and some breeds (collies, golden and Labrador retrievers, rottweilers, and German shepherds) appear to have a strong

Table I Benefits and risks of disease process with and without gonadectomy

\begin{tabular}{|c|c|c|}
\hline Benefit & Risk with gonadectomy & Risk without gonadectomy \\
\hline \multirow[t]{2}{*}{ Longevity in dogs } & Males: $13.8 \%$ increase in life span & - \\
\hline & Females: $26.3 \%$ increase in lifespan & \\
\hline \multirow[t]{2}{*}{ Pyometra } & 0 & Dogs: $25 \%-66 \%$ in those over $9-10$ years old \\
\hline & & Cats: risk unknown, but less than in dogs \\
\hline \multirow[t]{2}{*}{ Mammary tumors } & Dogs: $0.5 \%$ if prior to the first estrus & Dogs: $23 \%-63 \%$, with $50 \%$ being malignant \\
\hline & Cats: $86 \%$ decreased risk if before I year & $\begin{array}{l}\text { Cats: half the risk of dogs, with } 85 \%-93 \% \text { being malignant } \\
\text { and } 80 \% \text { already metastasized when diagnosed }\end{array}$ \\
\hline \multirow[t]{4}{*}{ Benign prostatic hyperplasia } & 0 & $75 \%-80 \%$ of intact dogs by 6 years: predisposes to other \\
\hline & & life-threatening prostate diseases \\
\hline & & $95 \%-100 \%$ of intact dogs by 9 years: predisposes to \\
\hline & & other life-threatening prostate diseases \\
\hline Testicular neoplasia & 0 & Risk unknown, but $<$ I\% will die from tumor \\
\hline
\end{tabular}


predilection for pyometra (Table 1). ${ }^{28-30}$ Complete removal of the ovaries and uterus of female dogs prevents pyometra from occurring.

In male dogs, there are several nonneoplastic diseases of the prostate that may occur with some frequency in dogs. Benign prostatic hyperplasia is the most common, and is reported to be evident in $75 \%-80 \%$ of intact dogs by 6 years of age and in $95 \%-100 \%$ of intact dogs by 9 years of age (Table 1). ${ }^{25,31-33}$ Dogs with benign prostatic hyperplasia are predisposed to prostatitis, which can result in life-threatening prostatic abscesses and infected prostatic cysts. ${ }^{6,734,35}$ Prostatic cysts and paraprostatic cysts can also result from benign prostatic hyperplasia. ${ }^{25,36-38}$ Castration is an effective treatment for benign prostatic hyperplasia. ${ }^{36,39,40}$ Additionally, castration is an effective preventive. ${ }^{38}$ Intact male cats only rarely are affected by prostatic disorders. ${ }^{41}$

\section{Urinary tract disorders}

Female dogs that are spayed are at greater risk for urethral sphincter-mechanism incompetence, which can result in urinary incontinence, than are intact female dogs. ${ }^{42-47}$ Concerns exist regarding early age gonadectomy in female dogs, because of a possible increased risk of urinary incontinence. Several studies have looked at this issue, and have had somewhat similar findings in that the risk of urinary incontinence increases after ovariohysterectomy, although the studies differed as to the timing of gonadectomy and its effect on incontinence ${ }^{43,47}$ One such study demonstrated that the greatest risk of urinary incontinence was for pups spayed before 3 months of age..$^{48}$ The authors of that study recommend avoiding gonadectomy until 3-4 months of age, if possible, recognizing that in sheltering situations this may not always be possible. A recent study evaluating the prevalence of urinary incontinence in 566 spayed dogs found that the risk of acquired urinary incontinence to be $5.12 \%{ }^{49}$ No significant difference in the age at the time of ovariohysterectomy between continent and incontinent dogs was identified; however, the incontinence rate of small dogs was $1.37 \%$ and $9.12 \%$ for dogs $\geq 15 \mathrm{~kg}$ (medium and large dogs), respectively. Since all dogs of the study were older than 12 weeks of age when spayed, the authors were unable to make any statements regarding the risk of urinary incontinence of dogs spayed younger than 3 months of age. Urinary incontinence does not appear to be a problem in female cats following ovariohysterectomy. ${ }^{44}$

\section{Lymphoma}

Lymphoma is a tumor that originates most commonly in lymphoid tissue, but may arise in any tissue in the body. ${ }^{50-52}$
Concerns have been raised about an increased risk of lymphoma in spayed/castrated dogs, and recent studies have examined the issue. One study examined the effect of sex and hormones on lymphoma using 14,573 case-control pairs of dogs identified based on breed and age from the Veterinary Medical DataBases (database of over 7 million records submitted by 26 universities). ${ }^{53}$ The study found that intact males were at the greatest risk for development of lymphoma (odds ratio 1.32) compared to intact females, castrated males, or spayed females. Age at the time of gonadectomy was not discussed.

The results of a study of vizsla-breed dogs were conflicting compared to the first study. ${ }^{54}$ Using an online survey of vizsla breeders to evaluate risk of several types of cancer, the study found that the odds of gonadectomized dogs having lymphoma or lymphosarcoma were higher (4.3 times) than those of sexually intact dogs. When examining the raw data from the study, however, the findings of the study result from the fact that the risk of lymphoma in dogs spayed after 12 months of age was higher (1.1\%) than the other spayed group (spayed $<12$ months of age $-0.3 \%$ ) or the intact group $(0.1 \%)$, which had similar risks (Table 2 ).

Another study of 759 golden retrievers revealed findings that were different than the other studies.$^{55}$ In this study, the rate of lymphosarcoma in intact male dogs was less than that of dogs castrated when less than 12 months of age. In dogs castrated $>12$ months of age, the risk of lymphoma was 0 versus $3.5 \%$ in intact dogs, and $9.6 \%$ in males castrated at or before a year of age. There were no differences relative to neuter status in female dogs (Table 2). The results of this study would suggest that male golden retriever dogs should be castrated just after a year of age to reduce the risk of lymphoma. A recent study of 1,500 Labrador retriever dogs found that the risk of lymphosarcoma was not higher at any neuter time period compared with intact animals for either males or females (Table 2). ${ }^{56}$

These studies illustrate that the findings of one breedspecific study cannot be extrapolated to the population as a whole, or to other breeds, since certain types of cancer (or other diseases/conditions) naturally occur more frequently in certain breeds than in others. Therefore, studies examining the effects of gonadectomy in a specific breed are only applicable to other dogs of the same breed. Studies that examine the population as a whole can typically be applied to the entire population of animals, recognizing that some breeds may respond differently than the population as a whole. In the cat, there are no studies suggesting any association between spaying/castrating and lymphoma. 
Table 2 Breed-specific lifetime risk of disease processes based on neuter status and timing of gonadectomy

\begin{tabular}{|c|c|c|c|c|c|}
\hline Breed & Sex & Risk & Gonadectomy $\leq 12$ months & Gonadectomy $>12$ months & Intact \\
\hline \multirow[t]{2}{*}{ Rottweiler } & $M$ & OSA & $28 \%$ & - & $8 \%$ \\
\hline & $\mathrm{F}$ & & $25 \%$ & - & $8 \%$ \\
\hline Golden retriever & M & Hip dysplasia & $10.2 \%$ & $3.1 \%$ & $5.1 \%$ \\
\hline \multirow[t]{2}{*}{ Golden retriever } & M & $C C L$ rupture & $5.1 \%$ & $1.4 \%$ & 0 \\
\hline & $\mathrm{F}$ & & $7.7 \%$ & 0 & 0 \\
\hline Golden retriever & M & LSA & $9.6 \%$ & 0 & $3.5 \%$ \\
\hline Golden retriever & $\mathrm{F}$ & HSA & $1.8 \%$ & $7.4 \%$ & $1.6 \%$ \\
\hline Golden retriever & $\mathrm{F}$ & MCT & $2.3 \%$ & $5.7 \%$ & 0 \\
\hline \multirow[t]{2}{*}{ Labrador retriever } & M & CCL rupture & $<6 m-7.6 \%$ & $12-23 m-1.9 \%$ & $2.3 \%$ \\
\hline & & & $6-11 m-2.8 \%$ & $2-8 y-0$ & \\
\hline \multirow[t]{2}{*}{ Labrador retriever } & M & Elbow dysplasia & $<6 \mathrm{~m}-4.2 \%$ & $12-23 m-0$ & $0.6 \%$ \\
\hline & & & $6-11 m-0$ & $2-8 y-2.2 \%$ & \\
\hline \multirow[t]{2}{*}{ Labrador retriever } & $\mathrm{F}$ & Hip dysplasia & $<6 m-5.4 \%$ & $12-23 m-4.3 \%$ & $1.7 \%$ \\
\hline & & & $6-11 m-5.1 \%$ & $2-8 y-0$ & \\
\hline \multirow[t]{2}{*}{ Vizsla } & M & LSA & $0.3 \%$ & $0.4 \%$ & $0.2 \%$ \\
\hline & $\mathrm{F}$ & & $0.3 \%$ & $1.1 \%$ & $0.1 \%$ \\
\hline \multirow[t]{2}{*}{ Vizsla } & M & HSA & 0 & $0.6 \%$ & $0.4 \%$ \\
\hline & $\mathrm{F}$ & & $0.5 \%$ & $1.1 \%$ & $0.1 \%$ \\
\hline \multirow[t]{2}{*}{ Vizsla } & M & МСТ & $0.5 \%$ & $1.3 \%$ & $0.5 \%$ \\
\hline & $\mathrm{F}$ & & $1.1 \%$ & $1.9 \%$ & $0.6 \%$ \\
\hline
\end{tabular}

Abbreviations: M, male; F, female; OSA, osteosarcoma; CCL, cranial cruciate ligament; LSA, lymphoma/lymphosarcoma; HSA, hemangiosarcoma; MCT, mast-cell tumor; $\mathrm{m}$, months of age; $y$, years of age.

\section{Hemangiosarcoma}

One of the major causes of death in certain breeds of dogs, including boxers, Labrador and golden retrievers, and German shepherds, is splenic hemangiosarcoma, which accounts for approximately $2 \%$ of all canine tumors. ${ }^{57-60}$ Three recent breed-specific studies have reported on neuter status and the risk of hemangiosarcoma (Table 2). In vizslas, the risk of hemangiosarcoma was greatest in females spayed after 12 months of age (1.1\%) and lowest in the intact dogs $(0.1 \%){ }^{54}$ Females spayed before 12 months of age had a risk of $0.5 \%$. In male vizslas, the risk was greatest in those castrated after 12 months of age $(0.6 \%)$ and lowest in those castrated before 12 months of age (0), while the risk was $0.4 \%$ in the intact males. The study of golden retriever dogs found similar results in the female dogs. ${ }^{55}$ In that study, females spayed after 12 months of age had a risk of $7.4 \%$, which was markedly higher than in dogs spayed prior to a year of age $(1.8 \%)$ or intact females $(1.6 \%)$. In males, differences were not seen between neuter status groups and the risk of hemangiosarcoma. In an older, agematched, case-controlled study of multiple breeds (92 dogs with hemangiosarcoma compared to 1,369 group-matched controls), gonadectomized females were found to be at a 2.2-time-greater risk compared to intact females for splenic hemangiosarcoma, although age at the time of gonadectomy was not discussed. ${ }^{61}$ In the Labrador retriever study, the risk of hemangiosarcoma was not found to be higher at any neuter period compared with those remaining intact for either male or female dogs. ${ }^{56}$

While the overall risk of hemangiosarcoma is low in the general population, the results of the golden retriever study should be kept in mind when discussing timing of spaying, and efforts should be made to spay these dogs before 1 year of age to potentially decrease the risk of splenic hemangiosarcoma. Splenic hemangiosarcoma occurs infrequently in cats, and no known association with gonadectomy could be identified in the literature.

\section{Osteosarcoma}

The most common bone tumor in dogs is osteosarcoma, and it is a common cause of death in medium-size and largeand giant-breed dogs. ${ }^{62-65}$ The prognosis for osteosarcoma remains poor, with median survival rates of 5-18 months. ${ }^{64,65}$ Concerns have been expressed that breeds that are predisposed to osteosarcoma may be at increased risk if they have been spayed/castrated.

One study examining this issue involved a mail survey of owners of 683 rottweiler dogs. ${ }^{63}$ The study found that dogs that underwent a spay or castration before a year of age were 3.8 and 3.1 times, respectively, more likely to develop osteosarcoma compared to intact dogs. Sexually intact dogs of that study had an $8 \%$ risk of developing osteosarcoma compared with a $28 \%$ risk in males and a $25 \%$ risk in females gonadectomized before 1 year of age (Table 2). However, the age at 
the time of death was actually greater (despite the increased risk of death from osteosarcoma) for the gonadectomized dogs compared to the intact dogs among the dogs that were deceased at the time of the study. The higher overall cancer risk seen in the early gonadectomized dogs may be due to longer life spans.

A study of the Veterinary Medical DataBases examined the role of host risk factors, including breed and sex and neuter status, on the development of osteosarcoma. ${ }^{62}$ The case-controlled study (but not age- or sex-controlled) involved 3,062 purebred dogs with confirmed diagnosis of osteosarcoma compared to 3,959 purebred controls found that dogs that had undergone gonadectomy had twice the risk of developing osteosarcoma as intact dogs. There were no sex-related differences in risk. Increasing height was associated with an increased risk of osteosarcoma, as was increasing body weight when controlling for breed. No attempt was made to correlate increased body weight with neuter status (gonadectomized dogs tend to gain weight following gonadectomy). The authors speculated that there could be confounding factors that were not measured, such as diet, since owners of gonadectomized animals might be more health-conscious and more likely to supplement their dogs with minerals and vitamins, which could promote bone growth and increase osteosarcoma risk.

Findings of these studies are of concern, particularly in the rottweiler breed, but it remains to be seen whether these findings are confirmed in larger well-controlled prospective studies or in differing breeds. Recent studies in the golden and Labrador retriever and vizsla breeds reported no increased risk of osteosarcoma in gonadectomized dogs compared to intact dogs, which illustrates the difference between dog breeds and the danger of extrapolating findings from breedspecific studies to other breeds or the population as a whole. Osteosarcoma is an uncommon tumor in cats, and an association with gonadectomy in cats has not been identified. ${ }^{64}$

\section{Mast-cell tumor}

Mast-cell tumors are a very commonly seen type of skin tumor in dogs (and cats), with boxers, Boston terriers, golden retrievers, Labrador retrievers, and others demonstrating a breed disposition. ${ }^{65-68}$ While mast-cell tumors may account for a large portion of skin tumors seen in dogs, the actual risk of these tumors is estimated to be around $0.06 \%-0.13 \%$ in the general population. ${ }^{69,70}$ In the golden retriever breed, mast-cell tumors were seen in $2.4 \%$ of the dogs in one study. ${ }^{55}$ While no differences were seen in the risk of mastcell tumors in male dogs relative to neuter status, in female dogs the tumors were seen more frequently in dogs spayed after 1 year of age (5.7\%) compared to intact dogs (0). Dogs spayed before a year of age had a risk of $2.3 \%$ (Table 2).

Labrador retrievers that have been spayed or castrated have no greater risk of developing mast-cell tumors, regardless of the age at neutering, compared to intact Labrador retriever dogs. ${ }^{56}$ In the vizsla breed, gonadectomized male and female dogs had a higher risk of mast-cell tumors. ${ }^{54}$ Male dogs castrated after 1 year of age had the highest risk of mast-cell tumors (1.3\%), followed by dogs castrated before 1 year of age $(0.5 \%)$ or remaining intact $(0.5 \%)$. Similarly, females spayed after 1 year of age had a higher risk of mastcell tumors $(1.9 \%)$, whereas the risk in those spayed before 1 year of age was $1.1 \%$ and $0.6 \%$ in dogs remaining intact (Table 2).

Whether the findings of these studies apply to other breeds is unknown, but these studies would suggest that when gonadectomizing dogs of the vizsla and golden retriever breeds, it would be best to perform the procedure prior to a year of age if there is concern about an increased risk of mastcell tumors. There is no identifiable association with mast-cell tumors and spaying/castrating status in the literature in cats.

\section{Orthopedic disorders}

Questions have also been raised as to whether gonadectomy in dogs may result in an increased risk of hip disease. It is well known that hip dysplasia is a multifactorial disease that is influenced by environment, genetics, diet, and many other factors. ${ }^{71-76}$ In one study of 759 golden retriever dogs, the risk of hip dysplasia in females was not influenced by ovariohysterectomy or the timing of the procedure.$^{55}$ However, males castrated before 1 year of age had a higher risk $(10.2 \%)$ of hip dysplasia than intact dogs (5.1\%) or those castrated after 1 year of age (3.1\%).

A study of 1,500 Labrador retrievers identified no difference in the risk of hip dysplasia in males at any neuter period compared to intact dogs. ${ }^{56}$ In females, however, the risk of developing hip dysplasia was higher for those spayed at $<6$ months (5.4\%), 6-11 months (5.1\%), and 12-23 months (4.3\%) compared to intact females $(1.7 \%)$. The risk of hip dysplasia for those dogs spayed between 2 and 8 years was 0 .

Another study of 1,733 boxers that were studied for 8 years found that dogs that were spayed/castrated and then diagnosed with hip dysplasia within 6 months of gonadectomy were 1.5 times more likely to develop lameness, and that those housed on slippery floors were 1.6 times more likely to develop hip dysplasia. ${ }^{77}$ Dogs from litters with high preweaning mortality 
rates had twice the risk of hip dysplasia. Obesity is another factor that may contribute to hip-dysplasia development and it is well documented that after spaying/castrating dogs tend to gain weight, although the timing of gonadectomy does not appear to influence the risk of becoming overweight. ${ }^{78}$ These studies demonstrate the need for keeping pets at a healthy weight, and also show that hip dysplasia is indeed a multifactorial disease. Gonadectomy is just one factor that may play a role in the development of hip dysplasia.

Studies have also suggested that gonadectomy may influence the risk of cranial cruciate ligament injuries. In particular, four studies of note have specifically examined this issue. In the first, golden retrievers spayed/castrated before 1 year of age were found to have a significantly higher risk of cranial cruciate ligament rupture. ${ }^{55}$ Males and females gonadectomized before 1 year of age had a risk of $5.1 \%$ and $7.7 \%$, respectively, compared to a risk of $1.4 \%$ in late-castrated males and 0 in late-spayed females and intact males and females (Table 2). In the second retrospective study of 10,000 dogs with cranial cruciate ligament rupture, those dogs that had undergone gonadectomy (timing unknown) had a higher risk of rupture than intact dogs. ${ }^{79}$ The third study, also a retrospective study, of 3,218 dogs treated in one practice found that gonadectomized dogs (timing unknown) had a 2.1-fold-greater risk of ligament rupture compared to intact dogs. ${ }^{80}$ Based upon these studies, it would appear that gonadectomy does play a role in cranial cruciate ligament rupture, although the effect of body condition was not examined in these studies. A fourth study in Labrador retrievers found that males castrated before 6 months of age had a higher risk ( $7.6 \%$ ) of developing cranial cruciate ligament rupture compared to intact males (2.3\%) (Table 2). ${ }^{56}$ This study did examine body-condition score (BCS). A mean $\mathrm{BCS}$ of both castrated and intact males with cranial cruciate ligament rupture was 6 compared to a BCS of 5 in the castrated and intact males without rupture. No differences were seen among female dogs with regard to the risk of cranial cruciate ligament rupture and timing of spaying compared to intact females.

Elbow dysplasia in male Labrador retrievers is seen more frequently in males castrated at $<6$ months $(4.2 \%)$ and between 2 and 8 years $(2.2 \%)$ compared to intact males $(0.6 \%)$. Elbow dysplasia was not seen in any males castrated from 6 to 23 months of age in a study of 1,500 Labrador retrievers. ${ }^{56}$ No differences were seen in female Labradors at any spaying age interval compared to intact dogs.

Concerns have been expressed by some veterinarians and laypersons about an apparent increased risk of capital physeal fractures in adult castrated male cats and its possible relationship to castration. The fact that physeal closure is delayed in cats (and dogs) that are gonadectomized early in life $\mathrm{e}^{81,82}$ has been suggested as the explanation for the increased risk in these cats. In the largest series of cases reported, 25 of 26 cats with spontaneous capital physeal fractures were castrated males. ${ }^{83}$ Fourteen of 16 cats for which the age at castration was known were castrated before 6 months of age. When compared to age- and sex-matched control cats, body weight at the time of initial exam was significantly greater in the affected cats $(12.3 \pm 2.6 \mathrm{lb}[5.6 \pm 1.2 \mathrm{~kg}])$ than control cats $(9.9 \pm 6.4 \mathrm{lb}[4.5 \pm 2.9 \mathrm{~kg}])$. The authors suggested that an abnormally high body weight was a risk factor for a slipped capital physeal fracture, as was neuter status, age, and delayed physeal closure (delayed in cats castrated at 7 weeks or 7 months of age). Another study of cats with slipped capital physes similarly found that nine of ten cats for which weights were recorded were considered to be obese or overweight. ${ }^{84}$ Additionally, in that study, three of 13 cats were Siamese cats $(23 \%)$, which was considerably greater than the percentage of Siamese cats in the control population (5\%).

Although this type of fracture is rare, good client education is necessary, particularly with male cats that are castrated before a year of age, to prevent these cats from becoming overweight. It is well documented that cats gain weight following castrating (or spaying), so caloric reduction must be implemented to prevent cats from becoming overweight or obese. ${ }^{82}$ While another alternative is to wait until after a year of age to castrate male cats, many male cats will develop objectionable behaviors if castration is delayed beyond puberty. ${ }^{85}$

\section{Behavior}

Concerns regarding the effect of gonadectomy on behavior of dogs have been recently expressed. Following castration in dogs, there is a $90 \%$ decrease in roaming, a $70 \%$ decrease in mounting behavior, and a $60 \%$ decrease in aggression with other male dogs. ${ }^{86}$ In another study however, male dogs castrated before 5.5 months were found to have aggression toward family members, barking or growling at strangers, and excessive barking that bothered family members. ${ }^{48}$ These three behaviors were highly associated with one another. Other studies have reported similar mixed findings. ${ }^{87,88}$

Cats also demonstrate behavioral changes associated with gonadectomy. ${ }^{89}$ With male cats, castration before 5.5 months is associated with decreased sexual behavior and urine spraying, decreased aggression toward veterinarians, and increased frequency of hiding behaviors. In both male and female cats, gonadectomy before 5.5 months was associated with a decreased occurrence of shyness around 
strangers. Another study of 800 kittens randomly assigned to prepubertal gonadectomy (8-12 weeks) or traditional-age gonadectomy (6-8 months) found no difference in behavioral problems between groups after adoption. ${ }^{90}$ Kittens were followed frequently for 24 months after adoption, and the occurrence of inappropriate elimination, fearful behavior, non-play-related aggression, and destruction did not differ based upon timing of gonadectomy.

\section{Longevity}

The effect of gonadectomy on longevity in dogs has been expressed as a concern for dogs based upon studies from the human literature, in which females exposed to estrogens during the course of their lives tend to live longer than males who do not have this exposure..$^{91-93}$ Additionally, age-associated declines in testosterone levels are strongly independent predictors of mortality in older men. ${ }^{94}$ These concerns appear unfounded in dogs, however. A study of 40,139 dogs from the Veterinary Medical DataBases looking at life span and neuter status found that life expectancy increased by $26.3 \%$ in females and by $13.8 \%$ in males that were castrated.$^{95}$ This effect was consistent among different size classes of dogs. Dogs that were spayed/ castrated were more likely to die of immunomediated diseases and neoplasia, and less likely to die of trauma, infectious diseases, vascular diseases, and degenerative diseases.

A retrospective study of 119 exceptionally aged rottweilers ( $>13$ years) were compared with 186 rottweilers with an average life span for the breed ( 9.4 years) to determine whether neuter status played a role in living to an exceptional age. ${ }^{96}$ The study found that in females, neuter status did play a role in life span, with females having the longest ovary exposure (6.1-8.0 years) being 3.2 times more likely to reach an exceptional age compared to dogs that had shorter ovary exposure. There were multiple problems with the study, including a lack of randomization, and different time frames studied for the two populations, among others, that may have played a role in the outcome. If the findings of this study were found to be repeatable, it would appear that females of the rottweiler breed may possibly respond differently than the population of dogs as a whole (based on the study of over 40,000 dogs).

While the rottweiler study raises some interesting questions in that breed, results from the larger study of over 40,000 dogs would pertain to the dog population as a whole. Unless other large, well-designed studies prove otherwise, the effect of neuter status on longevity should be considered heavily by veterinarians who are counseling their clients as to the risks/benefits of gonadectomy.

\section{Discussion}

It becomes clear when examining the literature that there are numerous considerations that play into decision making as to the timing of spaying or castrating, especially with dogs. With cats, the overwhelming evidence would suggest that gonadectomy is safe in cats at any age over 6 weeks. Since cats of both sexes will gain weight after gonadectomy, it is crucial to maintain cats at a healthy weight so as to avoid weight-associated endocrine disease and potential for slipped capital physes in males.

In the dog, the timing of gonadectomy is less defined. Since longevity is increased in dogs that are gonadectomized, and since some life-threatening diseases (mammary neoplasia, pyometra, prostatic abscess, etc) can be avoided, those benefits would appear to take precedence over many of the concerns of other diseases that occur with lesser frequency. If possible, females, should not be spayed until they are 3-4 months of age to avoid an increased risk of urinary incontinence. For many breeds, the literature suggests it is safe to castrate males at any age above $6-8$ weeks of age.

Exceptions to these guidelines noted may include concern about osteosarcoma in the rottweiler, and possibly hip dysplasia in male golden retrievers, cranial cruciate ligament rupture in both male and female golden retrievers, and lymphoma in male golden retrievers. In these breeds, veterinarians may wish to wait until just after a year of age before gonadectomy if these concerns take precedence over longevity benefits and decreased risk of female reproductive diseases and neoplasia. With the female golden retriever, however, if attempting to decrease the risk of hemangiosarcoma and mast-cell tumor, then the dogs should undergo ovariohysterectomy before 1 year of age. The male Labrador retriever may be castrated at approximately 2 years of age to have the lowest risk of both cranial cruciate ligament disease and elbow dysplasia, although those castrated between 6 and 11 months of age have similar risk for both orthopedic diseases, as do intact dogs. To lower the risk of hip dysplasia in female Labrador retrievers, ovariohysterectomy may be performed at 2 years of age. In the vizsla breed, to further decrease the fairly low risk of lymphoma, hemangiosarcoma and mast-cell tumor, dogs should undergo gonadectomy before 12 months of age.

When the older literature, as well as newer studies, is examined, it is important to recognize that there are limitations to these studies, particularly with breed-specific studies. As demonstrated by the golden and Labrador retriever studies (very similar breeds), as well as the vizsla study, data from one specific study cannot be extrapolated to other breeds or the general population. Additionally, there are potentially 
confounding factors in these studies, such as the retrospective nature of the studies, population studied, housing and environment, feeding and exercise protocols, and weight, among others. In many studies in the literature, author bias may have played a role in the interpretation of data. Where possible, it is important to look at actual study data to draw independent conclusions. As more research is conducted into identifying breed-specific risks and benefits of spaying/castrating, veterinary decision making may become more complicated in the individual animal of certain breeds, particularly in light of mixed results regarding timing of gonadectomy to decrease the risk of various conditions within given breeds of dogs.

\section{Conclusion}

Gonadectomy has both benefits and risks. This is particularly true in the dog, where there seem to be more potential risks than in the cat. It is important for the veterinarian to weigh these risks against the benefits gained for each patient that presents for spaying or castrating. While the benefits likely heavily outweigh the risks for most patients, the considerations discussed in this paper should be kept in mind when determining the best age to spay or castrate pet dogs of certain breeds. One should use caution, however, when trying to extrapolate findings from one breed to other breeds, or to the general population of dogs as a whole, since studies from a single breed often have conflicting results when compared to findings from studies of other breeds or the general dog population.

\section{Disclosure}

The author reports no conflicts of interest in this work.

\section{References}

1. Schneider R, Dorn CR, Taylor DO. Factors influencing canine mammary cancer development and postsurgical survival. J Natl Cancer Inst. 1969;43:1249-1261.

2. Rutteman GR, Misdorp W. Hormonal background of canine and feline mammary tumors. J Reprod Fertil Suppl. 1993;47:483-487.

3. Henry CJ. Mammary cancer. In: Bonagura JD, Twedt DC, editors. Kirk's Current Veterinary Therapy. 14th ed. St Louis: Saunders Elsevier; 2009:363-368.

4. Dow C. The cystic hyperplasia-pyometra complex in the bitch. Vet Rec. 1958;70:1102-1108.

5. Smith FO. Pyometra. In: Bonagura JD, Twedt DC, editors. Kirk's Current Veterinary Therapy. 14th ed. St Louis: Saunders Elsevier; 2009:1008-1009.

6. Berry SJ, Strandberg JD, Saunders WJ, Coffey DS. Development of canine benign prostatic hyperplasia with age. Prostate. 1986;9:363-373.

7. Berry SJ, Coffey DS, Strandberg JD, Ewing LL. Effect of age, castration, and testosterone replacement on the development and restoration of canine benign prostatic hyperplasia. Prostate. 1986;9:295-302.

8. Sirinarumitr K. Medical treatment of benign prostatic hypertrophy and prostatitis in dogs. In: Bonagura JD, Twedt DC, editors. Kirk's Current Veterinary Therapy. 4th ed. St Louis: Saunders Elsevier; 2009: 1046-1048.
9. Stubbs WP, Bloomberg MS. Implications of early neutering in the dog and cat. Semin Vet Med Surg (Small Anim). 1995;10:8-12.

10. Kustritz MV. Early spay-neuter in the dog and cat. Vet Clin North Am Small Anim Pract. 1999;29:935-943.

11. Kustritz MV. Early spay-neuter: clinical considerations. Clin Tech Small Anim Pract. 2002;17:124-128.

12. Howe LM. Short-term results and complications of prepubertal gonadectomy in cats and dogs. J Am Vet Med Assoc. 1997;211: $57-62$.

13. Misdorp W. Canine mammary tumors: protective effect of late ovariectomy and stimulating effect of progestins. Vet $Q .1988 ; 10: 26-33$.

14. Chang SC, Chang CC, Chang TJ, Wong ML. Prognostic factors associated with survival two years after surgery in dogs with malignant mammary tumors: 79 cases (1998-2002). JAm Vet Med Assoc. 2005;227: $1625-1629$

15. Itoh $\mathrm{T}$, Uchida $\mathrm{K}$, Ishaikawa $\mathrm{K}$, et al. Clinicopathological survey of 101 canine mammary gland tumors: differences between small-breed dogs and others. J Vet Med Sci. 2005;67:345-347.

16. Moe L. Population-based incidence of mammary tumors in some dog breeds. J Reprod Fertil Suppl. 2001;57:439-443.

17. Moulton JE, Rosenblatt LS, Goldman M. Mammary tumors in a colony of beagle dogs. Vet Pathol. 1986;23:741-749.

18. Gilbertson SR, Kurzman ID, Zachrau RE, Hurvitz AI, Black MM. Canine mammary epithelial neoplasms: biological implications of morphologic characteristics assessed in 232 dogs. Vet Pathol. 1983;20: 127-142.

19. Sorenmo KU, Shofer FS, Goldschmidt MH. Effect of spaying and timing of spaying on survival of dogs with mammary carcinoma. J Vet Intern Med. 2000;14:266-270.

20. Beauvais W, Cardwell JM, Brodbelt DC. The effect of neutering on the risk of mammary tumours in dogs - a systematic review. J Small Anim Pract. 2012;53:314-322.

21. Overley B, Shofer FS, Goldschmidt MH, Sherer D, Sorenmo KU. Association between ovariohysterectomy and feline mammary carcinoma. J Vet Intern Med. 2005;19:560-563.

22. Johnston SD, Root Kustritz MV, Olson PN. Disorders of the canine testes and epididymes. In: Johnston SD, Root Kustritz MV, Olson PN, editors. Canine and Feline Theriogenology. Philadelphia: WB Saunders; 2001:312-332.

23. Cohen D, Reif JS, Brodey RS, Keiser H. Epidemiological analysis of the most prevalent sites and types of canine neoplasia observed in a veterinary hospital. Cancer Res. 1997;34:2859-2868.

24. Towle HA. Testes and scrotum. In: Tobias KM, Johnston SA, editors. Veterinary Surgery: Small Animal. St Louis: Elsevier Saunders; 2012:1907.

25. Heuter KJ. Diseases of the prostate. In: Morgan RV, editor. Handbook of Small Animal Practice. 5th ed. St Louis: Saunders Elsevier; 2008: 559-568.

26. Howe LM. Diseases of the uterus. In: Morgan RV, editor. Handbook of Small Animal Practice. 5th ed. St Louis: Saunders Elsevier; 2008: 578-581.

27. Biddle D, Macintire DK. Obstetrical emergencies. Clin Tech Small Anim Pract. 2000;15:88-93.

28. Johnston SD, Root Kustritz MV, Olsen PN. Disorders of the canine uterus and uterine tubes (oviducts). In: Johnston SD, Root Kustritz MV, Olson PN, editors. Canine and Feline Theriogenology. Philadelphia: WB Saunders; 2001:206-220.

29. Hagman R. New Aspects of Canine Pyometra: Studies on Epidemiology and Pathogenesis [doctoral thesis]. Uppsala, Sweden: Swedish University of Agricultural Sciences; 2004. Available from: http://pub. epsilon.slu.se/736/1/Avhandlingsramen_f\%C3\%B6r_n\%C3\%A4rpub likation_R.Hagman.pdf. Accessed June 30, 2014.

30. Hagman R, Lagerstedt AS, Hedhammar Å, Egenvall A. A breedmatched case-control study of potential risk-factors for canine pyometra. Theriogenology. 2001;17:1251-1257.

31. Barsanti JA, Finco DR. Canine prostatic diseases. Vet Clin North Am Small Anim Pract. 1986;16:587-599. 
32. Olson PN, Wrigley RH, Thrall MA, Husted PW. Disorders of the canine prostate gland: pathogenesis, diagnosis, and medical therapy. Compend Contin Educ Pract Vet. 1987;9:613-623.

33. Johnson SD, Kamolpatana K, Root-Kustritz MV, et al. Prostatic disorders in the dog. Anim Reprod Sci. 2000;60:405-415.

34. Sirinarumitr K. Benigh prostatic hypertrophy and prostatitis in dogs. In: Bonagura JD, Twedt DC, editors. Current Veterinary Therapy. 15th ed. St. Louis: Saunders Elsevier; 2014:1012-1015.

35. White RAS. Prostate. In: Tobias KM, Johnston SA, editors. Veterinary Surgery Small Animal. St. Louis: Saunders Elsevier; 2012:1934-1937.

36. Kutzler MA, Yeager A. Prostatic diseases. In Ettinger SJ, Feldman EC, editors. Textbook of Veterinary Internal Medicine. 6th ed. St Louis Elsevier Saunders; 2005:1809-1819.

37. Bray JP, White RAS, Williams JM. Partial resection and omentalization: A new technique for management of prostatic retention cysts in dogs. Vet Surg. 1997:76:202-209.

38. Black GM, Ling GV, Nyland TG, Baker T. Prevalence of prostatic cysts in adult, large-breed dogs. J Am Anim Hosp Assoc. 1998;34:177-180.

39. White RA, Williams JM. Intracapsular prostatic omentalization: a new technique for management of prostatic abscesses in dogs. Vet Surg. 1995;24:390-395.

40. Hardie EM, Barsanti JA, Rawlings CA. Complications of prostatic surgery. J Am Anim Hosp Assoc. 1984;20:50-56.

41. White RA. Prostate. In: Tobia KM, Johnston SA, editors. Veterinary Surgery: Small Animal. St Louis: Elsevier Saunders; 2012:1907.

42. Thrusfield MV, Holt PE, Muirhead RH. Acquired urinary incontinence in bitches: its risk and relationship to neutering practices. $J$ Small Anim Med. 1998;39:559-566.

43. Arnold S, Arnold P, Hubler M, Casal M, Rüsch P. Urinary incontinence in spayed female dogs: prevalence and breed predisposition. Schweiz Arch Tierheilkd. 1989;131:259-263.

44. Coates JR, Kerl ME. Micturition disorders. In: Morgan RV, editor Handbook of Small Animal Practice. St Louis: Saunders Elsevier 2008:540-550.

45. Gregory SP. Developments in the understanding of the pathophysiology of urethral sphincter mechanism incompetence in the bitch. Br Vet J. 1994;150:135-150.

46. Beauvais W, Cardwell JM, Brodbelt DC. The effect of neutering on the risk of urinary incontinence in bitches - a systematic review. J Small Anim Pract. 2012;53:198-204.

47. Stöcklin-Gautschi NM, Hässig M, Reichler IM, Hubler M, Arnold S. The relationship of urinary incontinence to early spaying in bitches. J Reprod Fertil Suppl. 2001;57:233-263.

48. Spain VC, Scarlett JM, Houpt KA. Long-term risks and benefits of earlyage gonadectomy in dogs. J Am Vet Med Assoc. 2004;224:380-387.

49. Forsee KM, Davis GJ, Mouat EE, Salmeri KR, Bastian RP. Evaluation of the prevalence of urinary incontinence in spayed female dogs: 566 cases (2003-2008). J Am Vet Med Assoc. 2013;242:959-962.

50. Vail DM, MacEwan EG. Spontaneously occurring tumors of companion animals as models for human cancer. Cancer Invest. 1985;18: 781-792.

51. Teske E, van Heerde P, Rutteman GR, Kurzman ID, Moore PF, MacEwen EG. Prognostic factors for treatment of malignant lymphoma in dogs. J Am Vet Med Assoc. 1994;205:1722-1728.

52. National Canine Cancer Foundation. Lymphoma. Available from: http:// www.wearethecure.org/lymphoma. Accessed June 30, 2014.

53. Villamil JA, Henry CJ, Hahn AW, Bryan JN, Tyler JW, Caldwell CW. Hormonal and sex impact on the epidemiology of canine lymphoma. J Cancer Epidemiol. 2009;2009:591753.

54. Zink MC, Farhoody P, Elser SE, Ruffini LD, Gibbons TA, Rieger RH. Evaluation of the risk and age of onset of cancer and behavioral disorders in gonadectomized vizslas. J Am Vet Med Assoc. 2014; 244:309-319.

55. Torres de la Riva G, Hart BL, Farver TB, et al. Neutering dogs: effects on joint disorders and cancers in golden retrievers. PLoS One. 2013;8:e55937.
56. Hart BL, Hart LA, Thigpen AP, Willits NH. Long-term health effects of neutering dogs: comparison of Labrador retrievers with golden retrievers. PLoS One. 2014;9:1-10.

57. Spangler WL, Kass PH. Pathologic factors affecting postsplenectomy survival in dogs. J Vet Intern Med. 1997;11:166-171.

58. Wood CA, Moore AS, Gliatto JM, Ablin LA, Berg RJ, Rand WM. Prognosis for dogs with stage I or II splenic hemangiosarcoma treated by splenectomy alone: 32 cases (1991-1993). J Am Anim Hosp Assoc. 1998;34:417-421.

59. Spangler WL. Disorders of the spleen. In: Morgan RV, editor. Handbook of Small Animal Practice. 5th ed. St Louis: Saunders Elsevier; 2008: 701-706.

60. Clifford CA, de Lorimier LP. Canine hemangiosarcoma. In: Bonagura JD, Twedt DC, editors. Current Veterinary Therapy. 14th ed. St Louis: Saunders Elsevier; 2009:328-331.

61. Prymak C, McKee LJ, Goldschmidt MH, Glickman LT. Epidemiologic, clinical, pathologic, and prognostic characteristics of splenic hemangiosarcoma and splenic hematoma in dogs: 217 cases (1985). J Am Vet Med Assoc. 1988;193:706-712.

62. Ru G, Terracini B, Glickman LT. Host risk factors for canine osteosarcoma. Vet J. 1998;156:31-39.

63. Cooley DM, Beranek BC, Schlittler DL, Glickman NW, Glickman LT, Waters DJ. Endogenous gonadal hormone exposure and bone sarcoma risk. Cancer Epidemiol Biomark Prev. 2002;11:1434-1440.

64. Ehrhart NP, Fan TM. Osteosarcoma. In: Bonagura JD, Twedt DC, editors. Current Veterinary Therapy. St Louis: Saunders Elsevier; 2009: 358-362.

65. Rostami M, Tateyama S, Uchida K, Naitou H, Yamaguchi R, Otsuka H. Tumors in domestic animals examined during a ten-year period (1980 to 1989) at Miyazaki University. J Vet Med Sci. 1994;56:403-405.

66. Mukaratirwa S, Chipunza J, Chitanga S, Chimonyo M, Bhebhe E. Canine cutaneous neoplasms: prevalence and influence of age, sex and site on the presence and potential malignancy of cutaneous neoplasms in dogs from Zimbabwe. J S Afr Vet Assoc. 2005;76:59-62.

67. Welle MM, Bley CR, Howard J, Rüfenacht S. Canine mast cell tumours: a review of the pathogenesis, clinical features, pathology and treatment. Vet Dermatol. 2008;19:321-339.

68. Tham DH, Vail DM. Mast cell tumors. In: Withrow SJ, Vail DM, editors. Small Animal Clinical Oncology. 4th ed. St Louis: Saunders; 2007:402.

69. Villamil JA, Henry CJ, Bryan JN, et al. Identification of the most common cutaneous neoplasms in dogs and evaluation of breed and age distributions for selected neoplasms. $J$ Am Vet Med Assoc. 2011;239: 960-965.

70. Dobson JM, Samuel S, Milstein H, Rogers K, Wood JL. Canine neoplasia in the UK: estimates of risk rates from a population of insured dogs. J Small Anim Pract. 2002;43:240-246.

71. Kowaleski MP. Diseases of joints and ligaments. In: Morgan RV, editor. Handbook of Small Animal Practice. St Louis: Saunders Elsevier; 2008:767-769.

72. Smith GK, Biery DN, Gregor TP. New concepts of coxofemoral joint stability and development of a clinical stress radiographic method for quantitating hip joint laxity in the dog. J Am Vet Med Assoc. 1990;196: $59-70$.

73. Todhunter RJ, Lust G. Hip dysplasia: pathogenesis. In: Slatter DH, editor. Textbook of Small Animal Surgery. 3rd ed. Philadelphia: WB Saunders; 2003:2009-2019.

74. Smith GK, Paster ER, Powers MY, et al. Lifelong diet restriction and radiographic evidence of osteoarthritis of the hip joint in dogs. $J \mathrm{Am}$ Vet Med Assoc. 2006;229:690-693.

75. Lust G. An overview of the pathogenesis of canine hip dysplasia. J Am Vet Med Assoc. 1997;210:1443-1445.

76. Smith GK, Mayhew PD, Kapatkin AS, McKelvie PJ, Shofer FS, GregorTP. Evaluation of risk factors for degenerative joint disease associated with hip dysplasia in German shepherd dogs, golden retrievers, Labrador retrievers, and rottweilers. $J$ Am Vet Med Assoc. 2001;219: $1719-1724$. 
77. van Hagen MA1, Ducro BJ, van den Broek J, Knol BW. Risk, risk factors, and heritability estimates of hind limb lameness caused by hip dysplasia in a birth cohort of boxers. Am J Vet Res. 2005;66: 307-312.

78. Lefebvre SL, Yang M, Wang M, Elliott DA, Buff PR, Lund EM. Effect of age at gonadectomy on the probability of dogs becoming overweight. J Am Vet Med Assoc. 2013;243:236-243.

79. Whitehair JG, Vasseur PB, Willits NH. Epidemiology of cranial cruciate ligament rupture in dogs. J Am Vet Med Assoc. 1993;203: 1016-1019.

80. Slauterbeck JR, Pankratz K, Xu KT, Bozeman SC, Hardy DM. Canine ovariohysterectomy and orchiectomy increases the prevalence of ACL injury. Clin Orthop Relat Res. 2004:301-305.

81. Stubbs WP, Bloomberg MS, Scruggs SL, Schille VM, Senior DF. Prepubertal gonadectomy in the domestic feline: effects on skeletal, physical, and behavioral development. Vet Surg. 1993;22:401.

82. Kustritz MV. Early spay-neuter in the dog and cat. Vet Clin North Am Small Anim Pract. 1999;29:935-943.

83. McNicholas WT, Wilkens BE, Blevins WE, et al. Spontaneous femoral capital physeal fractures in adult cats: 26 cases (1996-2001). J Am Vet Med Assoc. 2002;221:1731-1736.

84. Perry KL, Fordham A, Arthurs GI. Effect of neutering and breed on femoral and tibial physeal closure times in male and female domestic cats. J Feline Med Surg. 2014;16:149-156.

85. Hart BL, Eckstein RA. The role of gonadal hormones in the occurrence of objectionable behavior in dogs and cats. Appl Anim Behav Sci. 1997;52:331-344.

86. Hart BL. Problems with objectionable sociosexual behavior of dogs and cats: therapeutic use of castration and progestins. Compend Contin Educ Pract Vet. 1979;1:461-465.
87. Measuring behavior and temperament. Poster presented at: American Kennel Club Canine Health Foundation Biennial National Parent Club Canine Health Conference; October 21-23, 2005; St Louis, MO.

88. Roll A, Unshelm J. Aggressive conflicts among dogs and factors affecting them. Appl Anim Behav Sci. 1997;52:229-242.

89. Spain CV, Scarlett JM, Houpt KA. Long-term risks and benefits of earlyage gonadectomy in cats. J Am Vet Med Assoc. 2004;224:372-379.

90. Porters N, de Rooster H, Verschueren K, Polis I, Moons CP. Development of behavior in adopted shelter kittens after gonadectomy performed at an early age or at a traditional age. J Vet Behav. 2014;9: 196-206.

91. Viña J, Sastre J, Pallardó FV, Gambini J, Borrás C. Role of mitochondrial oxidative stress to explain the different longevity between genders. Protective effect of estrogens. Free Radic Res. 2006;40:1359-1365.

92. Horstman AM, Dillon EL, Urban RJ, Sheffield-Moore M. The role of androgens and estrogens on healthy aging and longevity. J Gerontol A Biol Sci Med Sci. 2012;67:1140-1152.

93. Viña F, Borrás C, Gambini J, Sastre J, Pallardó FV. Why females live longer than males? Importance of the upregulation of longevity-associated genes by oestrogenic compounds. FEBS Lett. 2005;579:2541-2545.

94. Maggio M, Laurentani F, Ceda GP, et al. Relationship between low levels of anabolic hormones and 6-year mortality in older men: the aging in the Chianti area (InCHIANTI) study. Arch Intern Med. 2007;167: 2249-2254.

95. Hoffman JM, Creevy KE, Promislow DE. Reproductive capability is associated with lifespan and cause of death in companion dogs. PLoS One. 2013;8:e61082.

96. Waters DJ, Kengeri SS, Clever B, et al. Exploring mechanism of sex differences in longevity: lifetime ovary exposure and exceptional longevity in dogs. Aging Cell. 2009;8:752-755.
Veterinary Medicine: Research and Reports

\section{Publish your work in this journal}

Veterinary Medicine: Research and Reports is an international, peer-reviewed, open access journal publishing original research, case reports, editorials, reviews and commentaries on all areas of veterinary medicine. The manuscript management system is completely online and includes a very quick and fair peer-review system.

\section{Dovepress}

Visit http://www.dovepress.com/testimonials.php to read real quotes from published authors. 